\title{
PESQUISA NA FORMAÇÃO DOCENTE: APRECIAÇÕES DE GRADUANDOS E PROFESSORES DO CURSO DE GEOGRAFIA DE UMA UNIVERSIDADE ESTADUAL DO CEARÁ
}

\author{
Pedro Wallas Soares de Araújo FELIX ${ }^{1}$ \\ Maria Soares da CUNHA ${ }^{2}$ \\ Mirelle Oliveira SILVA3
}

\begin{abstract}
Resumo
Esse trabalho se interessa pela concepção de pesquisa em um curso de formação docente. Esse artigo visa compreender como graduandos e professores do curso de Licenciatura Plena em Geografia da Universidade Regional do Cariri-URCA concebem o que é pesquisa e qual seu papel para a formação de um professor de Geografia. As questões principais levantadas são: a pesquisa se faz presente durante o curso e os licenciandos conseguem avaliar a sua contribuição no processo de formação docente? Como os professores avaliam e incluem a atividade de pesquisa em suas atividades? Para responder tais questões e atingir o objetivo foi realizado inicialmente levantamento bibliográfico, posteriormente foram aplicados formulários de questões, através de contato direto e email para discentes cursando o quinto e o oitavo semestres do curso e para docentes do curso de Geografia. Após essa etapa empírica, foram realizadas análise e tabulação dos dados. Os graduandos entendem a pesquisa e seu papel no processo de formação inicial. Porém muitos não demonstraram uma visão ampla de seu significado para a futura profissão de professor e até no desenvolvimento acadêmico. Os professores formadores detêm uma concepção rica e compatível com os pesquisadores do tema da pesquisa em seu princípio educativo.
\end{abstract}

Palavras-chave: Concepção dos sujeitos. Ensino/Pesquisa. Formação docente. Geografia. Importância da pesquisa.

\section{RESEARCH IN TEACHING TRAINING: ASSESSMENTS OF GRADUATES AND TEACHERS OF THE GEOGRAPHY COURSE OF A STATE UNIVERSITY OF CEARÁ}

\footnotetext{
Abstract

This work is interested in the conception of research in a teacher training course. The monograph aims to understand how undergraduates and teachers

${ }^{1}$ Mestrando pelo Programa de Pós-Graduação em Geografia da Universidade Federal da Paraíba (UFPB). E-mail: pedrowsaf@hotmail.com

2 Professora Associada da Universidade Federal do Cariri (URCA). Doutora em Geografia pela Universidade Federal do Ceará (UFC). E-mail: maria.soares@urca.br

3 Mestranda pelo Programa de Pós-Graduação em Geografia da Universidade Federal da Paraíba (UFPB). E-mail: mirellesilva18@gmail.com
} 
of the Full Degree in Geography course at the Regional University of Cariri conceive what is research and what is its role in the formation of a geography teacher. The main questions raised are: is the research present during the course and can undergraduates evaluate their contribution to the process of teacher education? How do teachers evaluate and include research activity in their activities? To answer these questions and achieve the objective, a bibliographic survey was initially performed, and later questionnaires were applied through direct contact and email to students attending the fifth and eighth semesters of the course and to teachers of the Geography course. After this empirical step, data analysis and tabulation were performed. Undergraduates understand research and its role in the initial training process. But many have not shown a broad view of its significance for the future profession of teacher and even in academic development. The teacher trainers have a rich conception and compatible with the researchers of the research theme in its educational principle. Many stressed the difficulty of working the research due to the student's difficulty in reading, theoretically grounding. Most include research in the disciplines they work. The research is important for the teacher is constantly updated and able to exercise teaching in a qualified way. Research really has an intrinsic link to teaching. Students and teachers biased research to achieve intellectual independence and lso to produce knowledge. In the process of formation, the research becomes even more relevant seeing that it will be the basis of future teachers to innovate their practices and the geography they will teach.

Keywords: Conception of the subjects. Teaching / Research. Teacher training. Geography. Importance of research.

\section{INVESTIGACIÓN EN FORMACIÓN DOCENTE: EVALUACIONES DE GRADUADOS Y PROFESORES DEL CURSO DE GEOGRAFÍA DE UNA UNIVERSIDAD DEL ESTADO DE CEARÁ}

\section{Resumen}

Este trabajo está interesado en el concepto de investigación en un curso de formación docente. Este artículo tiene como objetivo comprender cómo los graduados y profesores del Curso de Grado Completo en Geografía en la Universidad Regional de Cariri-URCA conciben qué es la investigación y cuál es su papel para la formación de un profesor de Geografía. Las principales preguntas planteadas son: ¿̇está presente la investigación durante el curso y los graduados pueden evaluar su contribución al proceso de formación del profesorado? ¿Cómo evalúan e incluyen los maestros la actividad de investigación en sus actividades? Para responder a estas preguntas y lograr el objetivo, inicialmente se realizó una encuesta bibliográfica, luego se aplicaron formularios de preguntas, a través de contacto directo y correo electrónico para los estudiantes que asistieron al quinto y octavo semestre del curso y para los maestros del curso de Geografía. Después de esta etapa empírica, se realizaron análisis de datos y tabulación. Los graduados entienden la investigación y su papel en el proceso de capacitación inicial. Sin embargo, muchos no demostraron una visión amplia de su significado para la futura profesión de maestro e incluso en el desarrollo académico. Los formadores de docentes 
tienen una rica concepción que es compatible con los investigadores sobre el tema de investigación en su principio educativo.

Palabras clave: Concepción de los sujeitos. Docencia / Investigación. Formación del profesorado. Geografía. Importancia de la investigación.

\section{INTRODUÇÃO}

Esse artigo pretende discutir a formação docente sendo um tema que cada vez mais deve se fortalecer como alvo de pesquisas e eventos na academia. Nesse intuito é importante discutir o processo de formação docente e o que permite pensar em sua qualificação. Voltar-se aos aspectos de ensino e pesquisa pode ajudar a trazer novas questões e reflexões, principalmente em relação as práticas pedagógicas realizadas pelos professores formadores e aquelas dos sujeitos em formação.

A pesquisa no processo formativo é uma estratégia para a qualificação da educação, pois contribui para a formação dos sujeitos, para sua autonomia intelectual. $\mathrm{O}$ educar pela pesquisa se torna a especificidade mais própria da educação seja no âmbito escolar ou acadêmico (DEMO, 2015). É importante conhecer como se educa através da pesquisa. Buscar a correlação entre essas ações requer um pensamento crítico sobre a ação que os sujeitos estão realizando, podendo contribuir para ter uma continuidade mais qualificada nessa busca pelo saber. Dentro desse contexto, é relevante procurar uma compreensão melhor no que está presente no ambiente universitário.

É durante a graduação que o aluno se depara com a pesquisa de forma mais aprofundada. Os graduandos das universidades públicas dispõem da pesquisa como processo de formação inicial, porém muitos podem não ter uma concepção da relevância que esta possui para seu desenvolvimento acadêmico. Nesse contexto, também foi analisada a concepção de pesquisa que os professores formadores detêm, para verificar como está sua relação teoria/empiria com a pesquisa.

Nessa perspectiva, surge uma questão: a pesquisa se faz realmente presente no processo educacional de uma formação inicial docente em Geografia como conceito chave? Pois se ela for ligada a formação inicial pode possibilitar uma construção de conhecimento mais qualificado, reflexivo e 
crítico, qualificando o saber geográfico dos sujeitos. O questionamento é o início do caminho para ter essas e outras respostas.

Assim, abordando a pesquisa no âmbito da Licenciatura em Geografia, buscamos compreender: como a pesquisa é realizada durante um curso de licenciatura em Geografia? Quando e como os discentes a realizam? Quais as percepções que os graduandos e professores possuem sobre a prática da pesquisa e seu papel no seu processo de formação/profissionalização? Essas são algumas das questões levantadas para serem investigadas.

Dessa forma, este estudo trata da pesquisa na formação inicial da licenciatura em Geografia e busca verificar como se dá esse diálogo no processo de formação. Visa ainda analisar a concepção de pesquisa e o seu papel na formação docente de graduandos/professores no curso de licenciatura em Geografia na Universidade Regional do Cariri - URCA. Indagamos ainda: qual a importância e o papel da pesquisa para um curso de formação de professores? Como a pesquisa está sendo trabalhada no Curso de Licenciatura em Geografia? Qual a percepção de pesquisa que os sujeitos que o fazem detêm?

\section{O CAMINHO PERCORRIDO}

A Universidade Regional do Cariri (URCA) é uma universidade pública estadual, com sua sede central na cidade de Crato/CE, tendo outros campi nas cidades de Juazeiro do Norte (CRAJUBAR) e Unidades Descentralizadas em Iguatu, Campos Sales e Missão Velha. Sendo um grande polo científico/educacional do interior do estado do Ceará. 
Figura 1 - Mapa de localização da Universidade Regional do Cariri - URCA

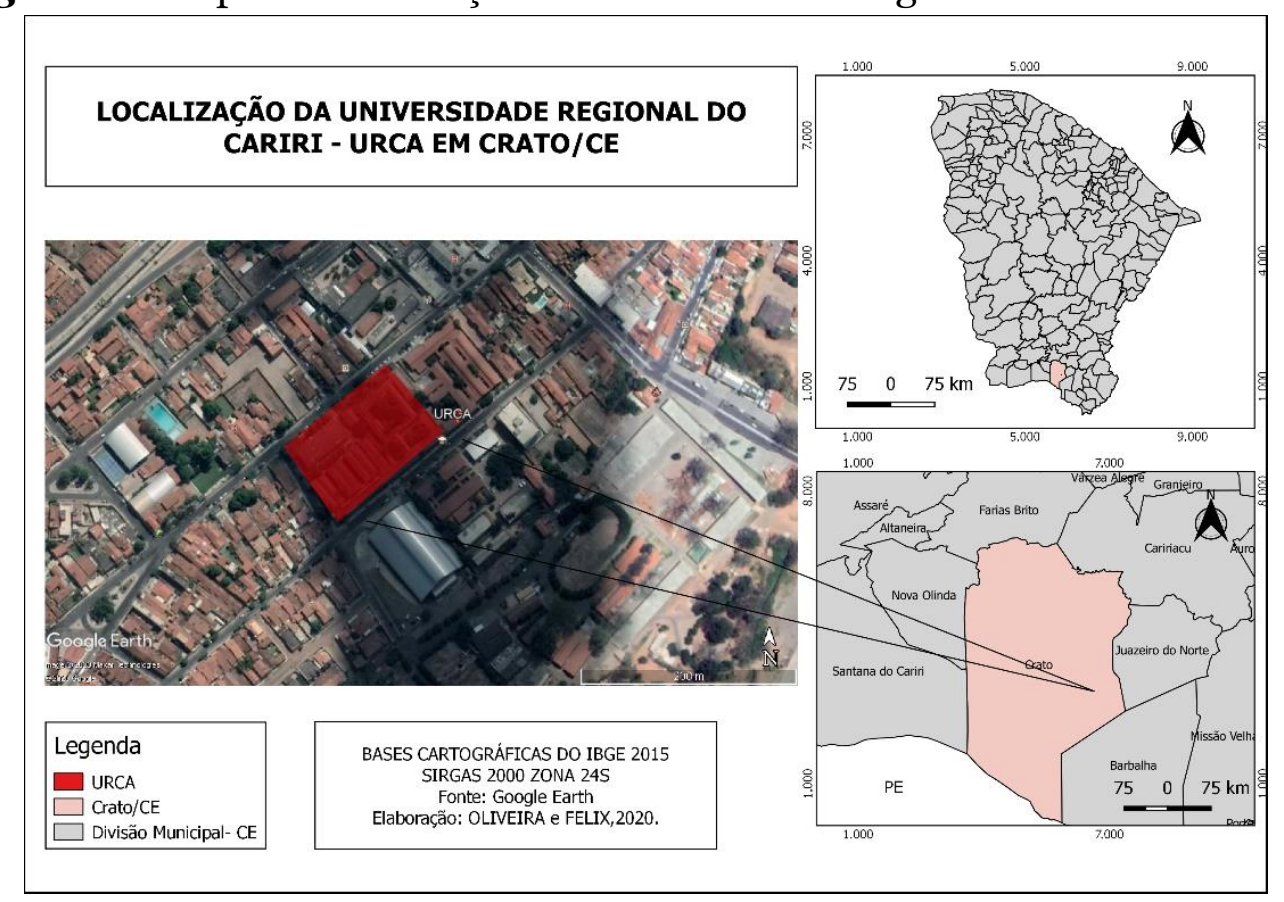

Fonte: OLIVEIRA e FELIX, 2020, adptado.

Esse trabalho caracteriza-se como uma pesquisa de cunho qualitativo e bibliográfico baseado em (GIROTTO; MORMUL, 2016, DEMO 2015, MOREIRA 2011) entre outros. As ideias e opiniões dos sujeitos são valorizadas como objetos de estudo e interpretação, colocando suas subjetividades para serem dialogadas com autores e trazendo reflexões sobre a temática abordada. Este trabalho “[...] não está preocupado em fazer inferências estatísticas, seu enfoque é descritivo e interpretativo ao invés de explanatório ou preditivo" (MOREIRA, 2011, p. 50).

Na pesquisa em questão, aplicou-se um formulário de entrevistas (pois a ideia inicial era a aplicação das perguntas através de contato direto). O formulário elaborado tem questões mistas (dissertativas e objetivas) e foi respondido por alunos e professores do Curso de Licenciatura em Geografia da URCA.

Os professores e alunos foram escolhidos partindo de dois critérios específicos: cursando disciplinas do $5^{\circ}$ semestre, posterior a duas disciplinas (Pesquisa Geográfica e Estudos Geoambientais) no qual o foco é a pesquisa e na qual os alunos farão uma pesquisa de forma direta e também por ser o começo da segunda metade do curso; os outros estudantes fazendo parte do $8^{\circ}$ semestre, 
momento em que já detém uma visão geral da formação docente em Geografia e que estão envolvidos na elaboração da pesquisa de monografia para encerrar o curso.

Os formulários juntamente com as entrevistas serviram de base para obter os resultados da concepção que esses sujeitos detêm sobre a pesquisa na formação docente em Geografia. Para aplicar o instrumento de pesquisa foram três momentos: primeiro, foi a definição de que semestres e como realizar a aplicação, sendo definido alunos e professores que vivenciam o $5^{\circ}$ e $8^{\circ}$ Semestres (2019.1), posteriormente foram enviados via email os formulários para os professores do $5^{\circ}$ e $8^{\circ}$ Semestres, turno manhã e noite.

Após as entrevistas e o recebimento das respostas foi feita a análise visando alcançar o objetivo proposto no trabalho e obter os resultados partindo das concepções dos sujeitos que compõem o curso de licenciatura de Geografia.

\section{REFERENCIAL TEÓRICO}

O processo de formação de professores de Geografia deve se pautar em atividades que ativem ações de problematização e reflexão por parte dos sujeitos que a compõe. Essas ações podem potencializar os discentes/docentes para fazer um projeto educacional mais qualificado para a sociedade (GIROTTO; MORMUL, 2016).

Bagno nos traz uma definição muito pertinente sobre a importância da pesquisa no avanço da ciência, dizendo

A pesquisa é simplesmente, o fundamento de toda e qualquer ciência digna deste nome. Quando alguém vier lhe falar de alguma 'ciência', portanto, fique logo atento e procure saber quais foram os últimos avanços dessa ciência, se não houve avanços é porque não houve pesquisa - e se não houve pesquisa é porque não houve ciência (2002, p.18).

Bagno liga o fazer pesquisa ao fazer ciência, com isso demonstra a grande relevância que esta detém para o avanço das técnicas e também dos sujeitos. $\mathrm{O}$ referido autor vai mais além e coloca "Se não houvesse pesquisa, todas as grandes invenções e descobertas científicas não teriam acontecido" (2002, p.19), nessa perspectiva ele aborda o objetivo da pesquisa dizendo que é "[...] 
investigação feita com o objetivo expresso de obter conhecimento específico e estruturado sobre um assunto preciso" (2002, p.18), isso enfatiza a pesquisa como processo de busca para chegar ao conhecimento.

A pesquisa no ambiente universitário é imprescindível em situações de ensino e aprendizagem. Com ela, há um processo contínuo de criação de perguntas, de problemas, e a busca de obtenção das respostas pode ajudar nos processos cognitivos e na qualificação do saber científico. Para fazer pesquisa é necessário ter curiosidade e rigor maior, que podem gerar inovações, chegando-se a algo que ainda era desconhecido (RIBEIRO, 2013). A curiosidade sobre o que está ao redor leva a busca por respostas partindo de dúvidas feitas sobre o cotidiano.

A pesquisa tem um princípio educativo como conceito chave que serve para trazer a criticidade e criatividade daqueles que o utilizam, como coloca Demo "Como princípio educativo pesquisa perfaz um dos esteios essenciais da educação emancipatória, que é o questionamento sistemático crítico e criativo" (DEMO, 2006, p.33).

Dessa forma a educação tem que fazer uso desse meio, pois "Não corresponderá o desafio da cidadania moderna, se permanecer na mera transmissão [...]" (ibdem., p.33), ou seja, apenas reproduzirá o que está posto. Pedro Demo (2015) enfatiza que a pesquisa proporciona para o professor a elaboração pessoal, sendo a busca da inovação fundamental para argumentar e contrapor-se, demonstrando ser um sujeito capaz, trazendo para si a emancipação intelectual necessária para a docência.

A questão da complementaridade do ensino com a pesquisa perpassa pela graduação do docente, porque é no processo de formação inicial que o discente tem maior proximidade com a investigação científica. Percebe-se com isso que "É salutar destacar que a atitude de pesquisador na educação básica possui ligação direta com a experiência que foi desenvolvida nas universidades" (SILVA; PINHEIRO, 2018, p.171). Esses autores alertam: "o divórcio entre prática pedagógica e pesquisa acadêmica é potencialmente capaz de fomentar alguns entraves aos processos de melhoria do par dialético ensinoaprendizagem (SILVA; PINHEIRO, 2018, p.173)”.

Um curso de licenciatura em Geografia é importante ter na sua 
metodologia a pesquisa interligada com o ensino, fazendo uma unidade entre essas duas vertentes que colaboram para o melhoramento da formação. A autonomia intelectual parte da unidade entre ensino e pesquisa.

O pressuposto para ensinar Geografia é desenvolver uma percepção mais aprofundada da realidade, tornando o saber geográfico mais qualificado sobretudo que está ao redor e melhorando o olhar geográfico sobre o cotidiano, mas esses processos ocorrem através da pesquisa. Conforme Girotto e Mormul “[...] ensinar geografia pressupõe reconhecer o raciocínio geográfico como um dos elementos fundantes do ser social" (2016, p.78). Constituir um conhecimento qualificado ou mais abrangente da realidade ocasiona uma maior dimensão do saber geográfico, como coloca Girotto e Mormul

Nosso processo de constituição se dá em relação contínua de desenvolvimento de nossa percepção sobre a Geografia dos objetos e sujeitos com os quais nos relacionamos diariamente. Nesta relação, vamos desenvolvendo capacidades que se referem à dimensão geográfica da realidade [...] (2016, p. 78)

A criticidade é um viés importante para a transformação do cotidiano das pessoas, isso pode ser obtido através dos conteúdos vistos em sala de aula a partir do momento que eles viram meios para interagir com a realidade. Deste modo o professor vai ajudar a instrumentalizar o aluno a compreender teoria/empiria da pesquisa.

Pensar a pesquisa é fundamental para a inovação profissional. Porquanto pesquisar é algo recorrente em diversas áreas, principalmente na era tecnológica que demanda uma maior rapidez e um grande número de pesquisas para o aprimoramento das técnicas e do conhecimento.

Para o professor exercer bem o ensinar pela pesquisa, antes de tudo tem que perceber e se assumir como pesquisador. Os cursos de formação de professores devem preparar os discentes que serão futuros docentes para ter sua subjetividade, ou seja, um sujeito capaz de pensar de ter a própria capacidade para se renovar. Como diz Santos "A pesquisa visa garantir a simbiose ensino e pesquisa. Ademais, tem a sua presença reclamada em face de sua condição de sustentáculo, prima rica para a captação de recursos e reconhecimento profissional, econômico e social do professor universitário” (2019, p.17). 
O graduando de licenciatura em Geografia está imerso em duas perspectivas que são: realizar o ato de pesquisa e instigar posteriormente seus alunos a fazerem pesquisas, dentro desse contexto é colocado: "A pesquisa como tal, tomada como princípio científico e educativo, maneira de saber fazer e de refazer conhecimento, bem como de educar; ressalta-se o desafio do questionamento, que é a energia vital da busca da inovação." (DEMO, 2015, p. 34). Ao enxergar a pesquisa como meio de aprender e ensinar, a concepção dessa passa ter uma maior importância nos cursos de formação de professores.

\section{RESULTADOS E DISCUSSÕES}

A pesquisa é de fundamental importância para o avanço nas questões de emancipação e independência intelectual dos sujeitos. A universidade pública tem a pesquisa no seu tripé de atuação, tendo uma grande relevância para o avanço desta nos seus objetivos institucionais.

Na graduação o discente deve ter a pesquisa no seu cotidiano. $\mathrm{O}$ ensino e a pesquisa se complementam, ou seja, são interligados, sendo necessário o discente de licenciatura ter a pesquisa e saber sua relevância para que possa trazer mais qualificação na sua profissão.

Nesse contexto, no levantamento empírico desse trabalho, a decisão foi verificar no Curso de Licenciatura de Geografia da URCA, no Projeto Pedagógico de Curso (PPC) que está vigente e a partir da participação de professores e alunos dessa licenciatura, qual ou quais as percepções de pesquisa e como esta é praticada neste curso de formação de professores. No primeiro tópico, será brevemente visto essa questão no PPC.

O Projeto Pedagógico do Curso (PPC) é o documento mais importante de qualquer curso por nortear as práticas dos docentes e do corpo discente. $\mathrm{O}$ atual PPC do curso de Licenciatura em Geografia da Universidade Regional do Cariri URCA foi oficializado no semestre de 2015.1, contendo a estrutura curricular, os programas das disciplinas e toda estrutura administrativa e pedagógica do curso de Geografia.

Voltado para questão do ensino com a pesquisa o PPC tem um princípio colocado para o curso de Geografia que é 
Fomentar a prática da pesquisa na formação inicial entendendo a mesma como um caminho metodológico para a docência, buscando a participação ativa do corpo discente, a dedicação dos docentes, o apoio institucional e o atendimento às exigências dos órgãos de fomento e regulamentação da ciência. (UNIVERSIDADE REGIONAL DO CARIRI, 2015, p.9)

A pesquisa perpassa desde o objetivo geral até os princípios estabelecidos no curso de Geografia, sendo uma das atividades centrais do processo de formação. No documento são citadas as ações para fazer os alunos serem investigadores críticos e assegurando a atualização científica. Portanto, a pesquisa foi estabelecida no curso e colocada em evidência.

A pesquisa ainda aparece em um dos objetivos específicos, sendo o processo de desenvolvimento do aluno para realizar essa prática tanto na graduação quanto no magistério, como é colocado no PPC "Desenvolver atividades teóricas-práticas que habilitem os alunos para o exercício da pesquisa e da ação, seja no magistério, na área de investigação científica ou na intervenção técnica da realidade” (UNIVERSIDADE REGIONAL DO CARIRI, 2015, p.10).

A pesquisa quando é colocada na formação docente de Geografia de forma efetiva proporciona ao professor se tornar pesquisador, tendo sua própria autonomia nas produções de conhecimento e emancipação para ensinar com qualidade o saber geográfico. Nesse sentido, ensinar é uma ação que necessita de preparação do docente, por essa razão a busca é necessária porque "A atitude do professor-pesquisador, ou seja, a pesquisa realizada pelo próprio professor é indispensável porque serve de base para a comparação com a pesquisa acadêmica” (SILVA; PINHEIRO, 2018, p.169). A pesquisa é essencial na formação e na atuação docente, servindo para auxiliar o professor na sua própria independência intelectual, auxiliando na formação de um professor reflexivo.

Deve se pensar sobre a formação do professor de Geografia, pois a mesma deve produzir de forma criativa aspectos educacionais, ressaltando a teoria/empiria sendo ligadas, como faz Girotto e Mormul (2016, p.103). "Não é possível pensar na formação de um professor de Geografia que não seja capaz de 
produzir práticas educativas que contribuam para o processo de reapropriação, pelo discurso e pela ação [...]”.

Foram enviados 9 (nove) formulários para os docentes formadores que estão lotados em disciplinas do $5^{\circ}$ e $8^{\circ}$ semestres do curso de Geografia no semestre 2019.1, no período de 23 a 26 de outubro de 2019. Destes, 7 retornaram com as questões respondidas, aparecendo suas respostas codificadas: $\mathrm{P}_{1}, \mathrm{P}_{2}, \mathrm{P}_{3}, \mathrm{P}_{4}, \mathrm{P}_{5}, \mathrm{P} 6$ e $\mathrm{P}_{7}$. Tendo por objetivo identificar a percepção de pesquisa dos sujeitos que assumem a docência, foram feitos alguns questionamentos sobre a importância da pesquisa na formação docente, como trabalham a pesquisa nas suas aulas ou com bolsistas, qual a primeira pesquisa realizada e entre outras. Todos os respondentes sinalizaram que a pesquisa é importante no curso de formação docente em Geografia.

Os professores reforçam a pesquisa como importante na formação dos sujeitos, sendo algo analisado como positivo. Isso demonstra o que foi ressaltado por Freire (1996) que não há ensino sem ter pesquisa, nem pesquisa sem ensino.

Na segunda pergunta, foi questionado a concepção dos respondentes sobre o papel da pesquisa na formação de um professor de Geografia. P1 ressaltou a contribuição que a pesquisa pode realizar na formação docente no caráter permanente de construir o conhecimento. O P2 enfatizou que a pesquisa é importante não só para o bacharel, mas também para o professor não se transformar em um repetidor, como fez a $\mathrm{P}_{3}$ também enfatizando a pesquisa na produção do conhecimento e deixando a reprodução. $\mathrm{P} 4$ trouxe a pesquisa junto da criatividade, pois sem a criatividade a pesquisa não modifica a Geografia. P5 colocou que é indispensável à pesquisa, o ensino e a extensão na formação docente. P6 trouxe o pensamento de alguns autores sobre a pesquisa, colocando que o ato de ensinar já é um ato de pesquisa. P7 enfatiza dizendo que a docência é uma atividade complexa e desafiadora, o que exige do professor uma constante disposição para aprender.

A eliminação da mera reprodução de conhecimento se configura como processo de avanço do professor pesquisador, segundo Demo (2009). E esta questão aparece ressaltado pelos professores nas respostas. Além disso, colocaram um aspecto que é a criatividade como resultado da junção ensino e 
pesquisa, o que também é um aspecto da inovação no exercício profissional. Os pesquisadores desse tema, como Demo (2015) colocou que o professor pesquisador consegue se atualizar de forma permanente.

Na terceira pergunta foi questionada a definição da ação de pesquisar. P1 definiu como uma ação de conhecimento de modo consciente. P2 coloca como produção de conhecimento, insatisfação das verdades postas. P3 ressaltou que é coletar dados e produzir conhecimento com eles. P5 também concorda que a ação de pesquisar consiste na produção de conhecimento e ainda acrescentou que ressignifica as formas de ler o mundo. $\mathrm{P} 4$ traz uma nova face, responde que é um diálogo permitindo ao aluno construir suas impressões com suas representações, construindo aprendizagens. P6 coloca que é um ato de descobertas e para gerar incertezas. $\mathrm{P}_{7}$ escreveu que a ação de pesquisar pode tornar o sujeito - professor capaz de refletir sobre sua prática profissional.

Essas respostas trazem uma ligação com as repostas anteriores, atrelando a pesquisa com a autonomia e produção do conhecimento. Colocaram ainda que é um diálogo que constrói aprendizagens. A base da educação é a pesquisa, pois sem ela não existe um educar qualificado, ressalta Demo (2015). Percebe-se que a pesquisa aguça a produção e faz a autonomia existir. E os professores do curso demonstram a riqueza da pesquisa no processo de formação.

Ao se perguntar quais tipos de pesquisas os docentes já realizaram no curso (exemplificando Iniciação Científica, pós-graduação, pesquisas internas e outros tipos de pesquisas) como foram colocados os exemplos no formulário, os respondentes assim se colocaram: (Quadro 1)

Quadro 1- Respostas dos professores sobre as pesquisas realizadas no curso de Geografia

\begin{tabular}{|c|c|c|c|c|}
\hline Professores & $\begin{array}{c}\text { Iniciação } \\
\text { Científica }\end{array}$ & $\begin{array}{c}\text { Orientação de } \\
\text { projetos Internos }\end{array}$ & $\begin{array}{c}\text { Pós- }^{\text {graduação }} \\
\text { P1 }\end{array}$ & $\begin{array}{c}\text { Outros } \\
\text { tipos }\end{array}$ \\
\hline $\mathrm{X}$ & $\mathrm{X}$ & $\mathrm{X}$ & \\
\hline $\mathrm{P} 2$ & $\mathrm{X}$ & $\mathrm{X}$ & $\mathrm{X}$ & $\mathrm{X}$ \\
\hline $\mathrm{P} 3$ & $\mathrm{X}$ & $\mathrm{X}$ & $\mathrm{X}$ & \\
\hline $\mathrm{P} 4$ & $\mathrm{X}$ & $\mathrm{X}$ & $\mathrm{X}$ & \\
\hline $\mathrm{P} 5$ & $\mathrm{X}$ & $\mathrm{X}$ & $\mathrm{X}$ & \\
\hline $\mathrm{P} 6$ & $\mathrm{X}$ & $\mathrm{X}$ & $\mathrm{X}$ & $\mathrm{X}$ \\
\hline $\mathrm{P} 7$ & $\mathrm{X}$ & $\mathrm{X}$ & $\mathrm{X}$ & $\mathrm{X}$ \\
\hline
\end{tabular}

Fonte: dados da pesquisa empírica, out. nov 2019. 
A Iniciação Científica (IC) é unânime entre os professores. É nítido que produzem pesquisas de outros programas, ampliando assim suas possibilidades de trazer reflexão importante para as suas aulas e atividades com alunos do curso de Geografia. Pois é importante perceber que a prática está indo de acordo com a teoria.

Na quinta pergunta apenas $\mathrm{P}_{5}$ disse que a pesquisa não é realizada pelos alunos nas disciplinas que ministra no curso. Os demais responderam que os discentes realizam nas suas disciplinas. P1 disse que realizam pesquisa-ação na sua disciplina. P2 colocou que realizam pesquisas pontuais. $\mathrm{P} 3$ disse que fazem pesquisa de material didático e de práticas. $\mathrm{P} 4$ ressaltou que fazem pesquisa pedagógica educativa. $\mathrm{P} 6$ disse que executam pesquisas experimentais. $\mathrm{P} 7$ disse que estimula a pesquisa na sua disciplina, mas poucos discentes aceitam o desafio.

Essa pergunta foi importante para notar quais tipos de pesquisa estão sendo realizadas nas disciplinas, além de trazer uma reflexão de que os alunos não fazem pesquisas em todas e também que não aceitam o desafio de pesquisar, no entender de um dos respondentes. Um dos objetivos do Projeto Político Pedagógico do Curso - PPC (2015, p.11) é "Desenvolver atividades teóricas-práticas que habilitem os alunos para o exercício da pesquisa e da ação, seja no magistério, na área de investigação científica ou na intervenção técnica da realidade". Importante perceber que os professores do curso procuram realizar esse objetivo em suas disciplinas. Os alunos ao fazerem pesquisas nas disciplinas abrem uma perspectiva crítico-reflexiva como diz Nóvoa (1995), ajudando na formação de um profissional que detém um saber geográfico qualificado.

Na sexta questão foi colocado para os docentes se estavam realizando pesquisas com alunos nesse semestre. Dos professores que responderam, apenas uma colocou que não estava realizando pesquisas com alunos no semestre de 2019.1. Nas pesquisas com bolsas remuneradas foi unânime a FUNCAP como fonte de financiamento das bolsas, também foi citado PIBICURCA e CNPQ. Tem que ressaltar que os professores citaram algumas pesquisas feitas sem bolsa, de forma voluntária. 
Fazer pesquisa de IC com bolsa é extremamente importante, tendo em vista que muitos alunos enfrentam dificuldades até para se deslocarem para Universidade. Pesquisar e ter uma remuneração para essa atividade aproxima o aluno do curso, amplia sua ligação, aumenta sua visão sobre como se trabalha a Geografia enquanto ciência, fazendo refletir sobre seu papel na sociedade. O aluno de licenciatura um dia poderá ensinar, e como diz Demo (2015) quem pesquisa necessita ensinar e quem ensina carece de pesquisar.

A sétima questão pede para o docente relembrar qual a primeira pesquisa que realizou, seja como aluno, seja assumindo o papel de professor (orientador). P1 disse que foi no quarto semestre do curso de Geografia e como docente em 2012. P2 disse 1994 e como docente 2003. P3 colocou que como aluna foi na disciplina de Geografia da População e na docência em 1998 na orientação. P5 como aluna no $6^{\circ}$ semestre e na docência logo ao ingressar. P6 fez como aluno quando se tornou bolsista do laboratório e como docente foi a pesquisa com o Geozine. $\mathrm{P}_{7}$ como discente disse que foi durante a especialização e como docente em 2005 no curso de Geografia.

Essa pergunta trouxe uma questão temporal para perceber desde quando estão habituados com a pesquisa. Nota-se que todos os respondentes fazem pesquisa desde a própria graduação. A pesquisa é importante na emancipação dos sujeitos como coloca Demo (2015). E essas pesquisas que fizeram e fazem contribuem para a profissão e atuação que exercem nos dias atuais.

$\mathrm{Na}$ oitava pergunta os professores responderam por unanimidade confirmando que fazer pesquisa contribuiu na sua profissão. P1 justificou que se deve pensar na educação centrada na pesquisa. P2 diz que aprofundou seu conhecimento nos processos e formas espaciais. P3 enfatizou dizendo que a pesquisa deu mais autonomia. $\mathrm{P} 4$ disse que tem muitas formas de aprender, não só pela pesquisa. $\mathrm{P}_{5}$ despertou com a pesquisa para enxergar além das aparências. P6 disse que a pesquisa ajudou a melhorar exemplos em sala de aula. $\mathrm{P} 7$ escreveu: "[...] entendo a formação numa dimensão reflexiva $e$ permanente, que decorre do pensamento crítico".

As respostas trouxeram a concepção de como a pesquisa pode contribuir na formação docente de maneira positiva e diversificada. Como coloca Cunha (2014, p.223) "[...] os pesquisadores da formação 
docente ressaltam o papel da investigação da prática social de ensinar tanto para melhorar o percurso formativo quanto para o desenvolvimento da profissão de professor [...]”. A pesquisa pode trazer avanços significativos para os futuros docentes.

\section{Formulário de pesquisa aos estudantes do $5^{\circ}$ semestre do curso de Geografia: principais questões}

Foram realizadas entrevistas com os discentes do $5^{\circ}$ semestre do curso de Geografia dos turnos da manhã e noite. $\mathrm{O} 5^{\circ}$ semestre da manhã tem uma média de 25 alunos por disciplina. $\mathrm{O} 5^{\circ}$ semestre da noite tem uma média de 35 alunos por disciplina, tendo 4 disciplinas obrigatórias (Geografia Urbana, Geografia Agrária, Fundamentos de Pedologia e Estágio Supervisionado I). Conseguimos obter as respostas de 15 alunos, porém trabalharemos com as respostas de 5 discentes dos dois turnos que foram escolhidos mediante a coerência dos seus escritos com as perguntas apresentadas e para uma adequação do trabalho as normas vigentes do periódico. Os formulários foram distribuídos individualmente ao final de uma das aulas em um dia de quarta-feira, manhã e noite, devidamente autorizada pela professora. As perguntas serão tidas como base para os resultados.

Os 5 alunos receberam um código para tratar as informações: A1, A2, A3, A4 e A5. Todos responderam por unanimidade: a pesquisa é importante no curso de licenciatura em Geografia.

Na segunda questão todos os alunos responderam que o conceito de pesquisa e o que é pesquisar foram trabalhados no curso, além de sinalizar que lembram o que é pesquisa. A maioria respondeu que isso foi estudado apenas no $4^{\circ}$ semestre. Outros mencionaram o $1^{\circ}$ e o $2^{\circ}$ semestres. De acordo com as respostas dos alunos, a pesquisa vem sendo debatida já no encerramento da primeira metade do curso, $4^{\circ}$ semestre, o que não condiz com o PPC, que apresenta ementas com essa discussão já no primeiro semestre, principalmente em Introdução ao Trabalho Científico Geográfico (ITCG). Isso é um fato que gera preocupação, pois poucos trouxeram outros semestres e a maior parte citando apenas um para explicar a importância da pesquisa.

$\mathrm{Na}$ terceira questão os alunos respondentes tiveram oportunidade de 
colocar o que entendem sobre pesquisa e pesquisar. A1 escreveu pesquisa como trabalho feito e pesquisar é o trabalho. A2 colocou "A pesquisa é o ato de ir atrás de explicações e pesquisar seria a ação". A3 foi logo dizendo que é busca aprofundada. A4 colocou que "A pesquisa é obter resultados e pesquisar ato de buscar". A5 concordou com isso na sua resposta e colocou pesquisar como busca de dados.

Ainda se levantou uma questão, pois todos os discentes disseram nas suas respostas que justificavam a pesquisa, seu conceito e seu papel, porém ainda tinha alguns estudantes que não se detinham a pesquisar, será apenas a falta de interesse? É uma questão importante para ser debatida dentro da formação, pois tem que ser verificado as causas do desinteresse dos alunos pela leitura e também pela pesquisa, sendo necessária essas práticas serem mais exercitadas durante a graduação. É mais uma questão que pode ser abordada em trabalhos futuros.

A quarta questão buscou saber sobre se estavam realizando ou já realizaram pesquisas no curso. O quadro 2 indica as respostas.

Quadro 2 - Situação dos alunos quanto a realização de pesquisa e bolsa de estudos

\begin{tabular}{|c|c|c|}
\hline Discentes & $\begin{array}{c}\text { Pesquisas com } \\
\text { bolsa }\end{array}$ & $\begin{array}{c}\text { Pesquisa voluntária ou } \\
\text { semBolsa }\end{array}$ \\
\hline $\mathrm{A} 1$ & & $\mathrm{X}$ \\
\hline $\mathrm{A} 2$ & $\mathrm{X}$ & $\mathrm{X}$ \\
\hline $\mathrm{A} 3$ & & $\mathrm{X}$ \\
\hline $\mathrm{A} 4$ & & $\mathrm{X}$ \\
\hline $\mathrm{A} 5$ & & \\
\hline
\end{tabular}

Fonte: dados da pesquisa empírica, out. nov 2019.

Dos 5 respondentes dessa questão 4 alunos não têm bolsa remunerada, não tendo um financiador para estimular suas pesquisas. Por outro lado, fazer pesquisa de forma voluntária, pode indicar o trabalho feito em disciplinas, que é um exercício importante para os graduandos. Essas respostas vão de acordo com o que está posto no PPC do curso de Geografia sobre o perfil do egresso que é "Capacidade, segurança e autonomia intelectual para produzir conhecimento, sendo um professor-pesquisador, autor de seu projeto profissional e de bens 
culturais (incluindo propostas pedagógicas e materiais de apoio à educação)" (Universidade Regional do Cariri, 2015, p.12), isso é relevante para perceber que estão seguindo um dos pontos sobre o perfil colocado.

Na quinta questão foi indagado: qual tipo de pesquisa os alunos já realizaram no curso. A2 disse que foi pesquisa científica. A3 escreveu a de extensão e iniciação científica. A4 disse apenas a da disciplina; A5 colocou apenas a bibliográfica.

Dos 5 alunos que responderam, 3 alunos não consideram as atividades ou trabalhos que fazem nas disciplinas como pesquisas. Todos deveriam fazer, por causa da ementa, pesquisa nas disciplinas de Pesquisa Geográfica com temas socioeconômicos e culturais e Estudos geoambientais: teoria e métodos da pesquisa geográfica. Isso tem que ser refletido, pois essas experiências de pesquisa estão para construir gradualmente a formação do discente pela ação de investigar.

A sexta questão quis saber se teriam aprendido algo ligado a profissão de professor fazendo pesquisa. A1 disse que foi a orientação. A2 mais enfática dizendo que foi a elaboração de formas de melhoramento da aprendizagem. A4 afirmou sendo a postura e a inovação. A5 disse apenas a utilização de outros recursos.

O que foi colocado pelos alunos foi importante para ressaltar a pesquisa como algo que está intrinsecamente ligado ao ensino, ajudando a trazer habilidades importantes para a profissão docente. Ao dar importância para a pesquisa na questão do aperfeiçoamento profissional e no seu conhecimento geográfico, os estudantes podem fazê-la quando forem professores. "É salutar destacar que a atitude de pesquisador na educação básica possui ligação direta com a experiência que foi desenvolvida nas universidades" (SILVA; PINHEIRO, 2018, p.171).

Ao perguntar se os professores do curso justificam a pesquisa, ou seja, sua importância e papel no curso ao trabalharem com as disciplinas, apenas um aluno não respondeu essa questão. A1 afirmou sim, porém disse que não teve ênfase. A2 disse que foi justificada no $1^{\circ}$ e $4^{\circ}$ semestres. A3 afirmou que sim, complementando que "muda muito a didática". A4 pontuou apenas com postura e inovação. A5 comentou dizendo que a pesquisa é importante. 
As respostas dessa sétima questão são relevantes para perceber se os docentes estão justificando a importância da pesquisa, e como os estudantes estão tratando isso ou compreendendo essa justificativa. Perceber que ainda lembram o que os docentes disseram é relevante para notar a aprendizagem que tiveram sobre a pesquisa.

A oitava questão buscou saber se conhecem alguma pesquisa sendo feita no curso. Alguns alunos não responderam essa questão. A2 disse sobre uma de Geomorfologia fluvial. Essa questão levanta uma preocupação: ou a maior parte dos respondentes não se atentou para a pergunta, não a compreendeu, ou realmente não conhecem e nem dialogam sobre pesquisas que estão sendo realizadas no curso. Não levaram em consideração as pesquisas feitas nas disciplinas, nem procuraram compreender alguma outra sendo realizada no curso, como as feitas pelos alunos de IC, por exemplo.

A nona questão procurou compreender se os alunos respondentes sabiam como se dá o passo a passo da pesquisa no curso. Alguns alunos como A1, A4 não responderam à questão. A2 enumerou com levantamento bibliográfico, análise de informações, campo e coleta de dados. A3 afirmou que tem que definir a pesquisa e registrar tudo com anotações. A5 foi sucinto dizendo "escolha do tema, recorte espacial, levantamento bibliográfico, prática de campo, conclusão".

Conhecer os passos para fazer uma pesquisa é primordial para quem já realizou uma ou vai realizar. Foi relevante conhecer que alguns sabem como se dá isso, registrando de maneira organizadas e sucinta o que fazer. Alguns alunos demonstraram não saber como se produz uma pesquisa e esse fato deve ser discutido no curso. Para o professor que está atuando, Ribeiro alerta: "A importância de pensar como são produzidos os conhecimentos por eles ensinados, e como são avaliados, pode ser um caminho para a reflexão pedagógica e epistemológica” (2013, p. 109).

A décima questão traz o objetivo central da pesquisa: entender o sentido da pesquisa nesse curso de licenciatura em Geografia. A1 disse que o professor também tem que ser pesquisador. A2 escreveu a necessidade de atualização de informações presentes no cotidiano. A3 afirmou que é para obter conhecimento e vir aprimorar com o passar do tempo. A4 disse apenas que o geógrafo é 
importante atuante no mundo atual. A5 escreveu o desenvolvimento do graduando para outras visões acadêmicas.

A maioria das respostas escritas pelos alunos demonstra o entendimento do sentido da pesquisa no curso. É relevante perceber isso porque demonstram terem uma compreensão desse processo investigativo. Com isso traz a reflexão de que a educação centrada na pesquisa consegue obter grandes resultados de aprendizagem e produção de conhecimento, proporciona ao docente uma capacidade maior e mais qualificada para exercer a docência e se manter enquanto pesquisador, pois o próprio professor precisa se reconhecer enquanto pesquisador para que a pesquisa possa haver no ensino.

A décima primeira pergunta indagou sobre a contribuição da pesquisa para o professor de Geografia. A1 disse que aumenta o conhecimento. A2 escreveu que ajuda no papel docente do mesmo. A3 colocou que é contribuir em todos os pontos positivos. A4 enfatizou que contribui no desenvolvimento teórico do professor. A5 colocou que desenvolve a criticidade.

A maioria dos alunos disse que a contribuição da pesquisa é no aumento do conhecimento, na compreensão dos conteúdos geográficos. Foi importante notar que eles têm essa compreensão da pesquisa porque a percebem como uma possibilidade de avanço na profissão docente pelo fato de deixá-los com embasamento, teórico e prático. Demo (2015) enfatiza que a pesquisa proporciona para o professor a elaboração pessoal, que ele se reconheça como sujeito capaz de ter autonomia, chegar a inovação, de argumentar e contraporse ao que lê, escuta, prática.

\section{Formulário de pesquisa aos estudantes do $8^{\circ}$. semestre do curso de geografia: principais questões}

Foram enviados 28 formulários para os discentes do $8^{\circ}$ semestre do curso matriculados no semestre 2019.1. Nos $8^{\circ}$ semestre no turno da manhã tem uma média de 20 alunos por disciplina (Geografia dos espaços mundiais, Domínios de Paisagens Brasileiras, Estágio Supervisionado IV e Estudos Monográficos II), no $8^{\circ}$ semestre da noite tem uma média de 27 alunos por disciplina. Do total dos 28 formulários enviados por email, apenas 10 formulários retornaram 
respondidos. Os formulários foram enviados no dia 30 de novembro de 2019, sendo reenviados emails nos dias 31 de outubro e 1 de novembro de 2019 para lembrarem de enviar os formulários com as questões respondidas.

Entretanto, vamos trabalhar com as respostas de 5 discentes que conseguiram colocar explicações pertinentes sobre as perguntas feitas. Aqui codificados com a letra $\mathrm{AC}$, aluno concludente, ( $\left.\mathrm{AC}_{1}, \mathrm{AC}_{2}, \mathrm{AC}_{3}, \mathrm{AC}_{4}, \mathrm{AC}_{5}\right)$ que responderam as questões, todos sinalizaram que a pesquisa é importante no curso de formação docente em Geografia. Mesmo sendo objetiva, sim e não, percebe-se que os alunos reconhecem e dão relevância à pesquisa no curso de licenciatura. Na segunda questão foi solicitado escreverem o conceito de pesquisa e o que é pesquisar, a partir do que foi trabalhado no curso. AC1 colocou que foram trabalhados no $2^{\circ}$ e $3^{\circ}$ semestres. AC2 disse que foram trabalhados no $4^{\circ}, 5^{\circ}$ e $7^{\circ}$. $\mathrm{AC}_{3}$ lembrou que foram $1^{\circ}, 3^{\circ}$ e $4^{\circ}$ semestres. $\mathrm{AC}_{4}$ colocou apenas o $4^{\circ}$ semestre. $\mathrm{AC}_{5}$ lembrou do $4^{\circ}, 5^{\circ}, 7^{\circ}$ e $8^{\circ}$ semestres.

Foi algo perceptível nas respostas da segunda questão dos alunos do $5^{\circ}$ semestre, como o $4^{\circ}$ semestre está sendo colocado sendo um dos momentos do curso que mais se trabalha o conceito de pesquisa. Os alunos do oitavo trouxeram mais outros, principalmente, o sétimo semestre. Interessante o fato do $7^{\circ}$ (sétimo) semestre, onde os alunos devem escrever um projeto de pesquisa, que alguns respondentes não o citaram como um momento de trabalhar a concepção de pesquisa. Isso ocorreu também com a não menção do oitavo semestre, momento em que a maioria dos respondentes se dedica a fazer a pesquisa. Por outro lado, ao aparecer para alguns esses semestres, pode indicar preocupação dos docentes em retomarem o conceito para falar da prática da pesquisa. "Em outras palavras, quando se cria condições objetivas para a formação de um professor-pesquisador, cria-se também uma nova compreensão coletiva, no campo educacional" (SILVA; PINHEIRO, 2018, p.171).

$\mathrm{Na}$ terceira questão, os respondentes escreveram o que entendem sobre pesquisa e pesquisar. AC1 colocou que é um método que pode ser feito tanto na academia quanto no cotidiano. $\mathrm{AC} 2$ disse que pesquisa é procurar e pesquisar é se aprofundar em determinado assunto. $\mathrm{AC}_{3}$ colocou que é a indagação, a busca por respostas. $\mathrm{AC}_{4}$ enfatizou que pesquisa é uma atividade bem planejada e sistemática, pesquisar é o ato de investigar. $\mathrm{AC}_{5}$ registrou que é o ato de 
conhecer o desconhecido.

Percebe-se que os alunos do $8^{\circ}$ tem uma visão mais ampla nas suas respostas. Provável que resulte do processo de aprendizagem nos três semestres de finalização do curso. Por isso é creditada como um processo de formação que os estudantes podem aprender no decorrer do curso, isso é um fato que pode ser notado nas respostas. Os alunos colocaram até sobre "ir além da profissão" ou "descobrir algo novo", com isso é nítido que para fazer pesquisa é necessário ter um rigor maior que pode gerar algo inovador, partindo e refletindo a partir do que ainda é desconhecido (RIBEIRO, 2013).

Na quarta questão, os alunos relembraram quais tipos de pesquisas já realizaram na graduação. AC1 disse que foi a pesquisa de Iniciação Científica. $\mathrm{AC} 2$ escreveu que foram de estágio e projetos de disciplinas. $\mathrm{AC}_{3}$ colocou projeto de análise geoambiental. $\mathrm{AC}_{4}$ disse pesquisa do tipo qualitativa pautada no método do materialismo histórico dialético.

Os discentes nessas respostas colocaram as pesquisas que realizaram nas disciplinas, sendo importante perceber que eles têm essas pesquisas como atividades importantes na sua formação, dando relevância para estas. Vale lembrar Demo (2015) dizendo que pesquisa no processo formativo é uma estratégia para a qualificação da educação, pois contribui para a formação dos sujeitos, para sua autonomia intelectual.

A quinta questão quis saber se já realizaram pesquisa em outra atividade, fora a da monografia. O quadro mostra os resultados. Somente dois alunos não responderam.

Quadro 3 - Pesquisas realizadas pelos alunos do curso de Geografia

\begin{tabular}{|c|c|c|c|}
\hline Discentes & $\begin{array}{c}\text { Pesquisa em outra } \\
\text { atividade }\end{array}$ & $\begin{array}{c}\text { Vínculo com } \\
\text { Bolsa }\end{array}$ & $\begin{array}{c}\text { Vínculo com } \\
\text { disciplina }\end{array}$ \\
\hline $\mathrm{AC} 1$ & $\mathrm{X}$ & $\mathrm{X}$ & $\mathrm{X}$ \\
\hline $\mathrm{AC} 2$ & $\mathrm{X}$ & $\mathrm{X}$ & \\
\hline $\mathrm{AC} 4$ & $\mathrm{X}$ & $\mathrm{X}$ & \\
\hline
\end{tabular}

Fonte: dados da pesquisa empírica, out. nov 2019.

A maioria dos alunos está realizando pesquisas e conseguiram bolsas para estimular sua continuidade na investigação. 
A sexta questão procurou saber se tinham aprendido alguma habilidade ligada a profissão de professor fazendo a pesquisa. AC1 disse que foi a capacidade de como futura professora ensinar meus alunos a também fazer pesquisa. AC2 foi sucinto dizendo que afirmaria apenas a investigação. $\mathrm{AC}_{3}$ enfatizou que foi principalmente a didática em sala de aula. $\mathrm{AC}_{4}$ colocou que foi a capacidade de investigar e compreender em uma visão crítica sobre o objeto de estudo.

Essa questão é muito importante porque nela percebe-se como está a aprendizagem dos alunos na docência através da pesquisa, notando que estão conseguindo aprender e avançar realizando pesquisa. Eles conseguem associar o exercício de pesquisar com o de ensinar, em várias habilidades em comum ou que reforçam a docência.

Na sétima questão buscou saber o conhecimento deles sobre as pesquisas realizadas na academia. 3 alunos responderam que não conheciam pesquisas sendo feitas, os demais responderam que sim. $\mathrm{AC} 1$ escreveu as pesquisas do laboratório de Análise Geoambiental (LAGEO). AC4 sintetizou dizendo que conhece a pesquisa sobre a Chapada do Araripe para além da paisagem: aula de campo como estratégia de ensino e aprendizagem. $\mathrm{AC}_{5}$ colocou que sabe de algumas monografias.

A oitava pergunta procurou indagar se os respondentes sabiam o passo a passo da pesquisa no curso. $\mathrm{AC} 1$ enumerou dizendo que era "identificando a área de interesse do tema que se queira trabalhar, identificar um recorte espacial, efetuar leituras sobre a temática, procurar orientação de um dos professores que trabalhem com o tema e elaborar o projeto de pesquisa e por fim fazer o ato de pesquisar para chegar aos resultados esperados". Aresposta indica que o aluno sabe os vários momentos e atividades envolvidas, provavelmente por seguir os próprios passos. $\mathrm{AC} 2$ disse "escolha do tema, metodologia, trabalho de campo e discussão de resultados". $\mathrm{AC}_{4}$ colocou "O primeiro passo é a realização do projeto da pesquisa onde será feito a escolha do problema a ser pesquisado feito, a definição e delimitação de um problema de pesquisa é preciso então definir os objetivos, logo após a formulação da hipótese, e feito a coleta de dados e então a análise e interpretação dos resultados". Como coloca Demo (2015, p.9). "A pesquisa inclui sempre a 
percepção emancipatória do sujeito que busca fazer e fazer-se oportunidade, à medida que começa a se reconstituir pelo questionamento sistemático da realidade $[\ldots . .$. ".

A nona pergunta questionou sobre o sentido de aprender a pesquisar num curso de licenciatura de Geografia. $\mathrm{AC} 1$ escreveu "O principal sentido de fazer pesquisa na universidade é formar professores-pesquisadores". $\mathrm{AC}_{2}$ discorreu colocando que "além de adquirir conhecimento, é necessário para estar preparado para adversidade da profissão". $\mathrm{AC}_{3}$ foi sucinta dizendo que acredita que acima de tudo o grande aprendizado que a pesquisa deixa como legado é aprendizagem. $\mathrm{AC}_{5}$ foi enfático dizendo que é importante, pois os cursos de licenciatura estão formandos professores para atuarem em sala de aula é de mera importância à pesquisa.

Com isso tem a concepção de que os discentes têm uma visão da pesquisa como algo inovador que proporciona conhecimento, tendo a possibilidade de instigar a criticidade, que é fundamental na carreira docente. Perceber também eles interligarem a pesquisa com o ensino é algo muito relevante, pois demonstra que quem ensina carece pesquisar e quem pesquisa carece ensinar (DEMO, 2015). Como já ressaltado "[...] a atitude de pesquisador na educação básica possui ligação direta com a experiência que foi desenvolvida nas universidades" (SILVA; PINHEIRO 2018, p.171).

A expectativa é que esses licenciandos espalhem o princípio educativo das pesquisas ao atuarem nas escolas, não sendo o transmissor que apenas reproduz conhecimentos e tendo assim, um papel fundamental na qualidade da formação de crianças e jovens.

A percepção que teve a partir das respostas dos alunos foi a maior facilidade que os estudantes da manhã ou que são bolsistas respondiam sobre a pesquisa, seja o conceito ou ato de pesquisar, acredito que por estarem mais próximos da pesquisa no seu cotidiano acabam tendo mais habilidade para responderem de forma mais aproximada o conceito de pesquisa.

Os professores deram um grande embasamento teórico para esta pesquisa, pois colocaram respostas contundentes que trouxeram boas reflexões e questões da pesquisa no curso de Geografia. Os docentes justificam a importância da pesquisa nas suas aulas, sabem como é o processo de pesquisa e 
também tem um grande referencial teórico sobre ensino e pesquisa. Contribuíram com isso para notar a importância da pesquisa quando é ensinada no curso e colocada como fundamental nas aulas.

Algumas preocupações apareceram nas respostas: a falta de estrutura e financiamento para realização de pesquisas por todos os alunos do curso. $\mathrm{O}$ desinteresse de alguns matriculados também é um problema para a realização de pesquisas rigorosas econtínuas no curso. Os obstáculos servem para valorizar ainda mais a pesquisa na formação docente porque se percebe que fazer pesquisa é um processo difícil, mas que precisa ser feito para se ter ciência, avanço do conhecimento geográfico e do profissional que atua na educação. Os estudos também fazem refletir que é um processo lento, mais os benefícios já são reconhecidos.

Reflexão e questões importantes que apareceram nesse processo de investigação: "O professor tem que sempre aprender"; "Como professor vai ensinar se não aprende primeiro?" "Como o docente vai ser mediador de um conhecimento se ele não realizou pesquisas para tê-lo?” O professor quando ensinar já estará fazendo pesquisa, pois não vai transmitir algo ou repassar, vai ensinar o que aprendeu, sendo um dos responsáveis pela construção qualificada do conhecimento dos alunos. Isso torna seu papel ainda mais relevante, por isso a necessidade de atualização constante e de aprendizagem permanente.

A formação docente como estágio inicial serve de base para toda a construção que o discente vai ter para sua vida enquanto docente. A pesquisa nesse estágio colabora para aumentar a criticidade e a desenvoltura deste sujeito quando tiver em sala de aula. Nesse contexto, o ensino e a pesquisa intrinsecamente ligados se configuram como principal base para o professor pesquisador

\section{CONSIDERAÇÕES FINAIS}

O caminho traçado na pesquisa buscou entender o sentido e o papel da pesquisa no curso de formação de professores de Geografia da URCA. Nesse sentido, foi possível perceber o quão importante é a pesquisa e como está imersa totalmente no ensino. A pesquisa é relevante no curso de licenciatura, pois ela 
faz avançar o conhecimento e está intrinsecamente ligada a profissão docente que necessita dela para avançar nos seus métodos, criatividade e ensino, também em sua formação de conteúdos de Geografia.

A pesquisa é importante tanto para ciência quanto para a educação porque ela pode tanto trazer descobertas científicas quanto também educar de forma completa. Nesse sentido a pesquisa contribui como expressão educativa para andar de olhos abertos, ler criticamente a realidade (DEMO 2002).

A pesquisa deve ser pensada como base, alicerce para a prática docente e fundamental para a emancipação dos sujeitos. Os alunos que participaram desse estudo demonstram nas suas respostas que fazer pesquisa é importante para exercer a docência. Porém poucos licenciandos refletem sobre como essa atividade está no cotidiano na vida acadêmica.

Foi possível verificar que os estudantes do Curso de Geografia que são bolsistas respondiam com mais facilidade sobre a pesquisa, apresentando conceitos mais amplos sobre o ato de pesquisar. Talvez por estarem mais próximos da pesquisa no seu cotidiano acabam tendo mais parâmetros para responder. Mas a pesquisa em si é tida pela maioria dos estudantes que responderam os formulários ainda como algo especial, não como atividade cotidiana de disciplinas, mas algo mais aprofundado como iniciação científica ou extensão.

Boa parte dos alunos não percebe a pesquisa em suas diferentes formas. Essas atividades precisam ser mais exercitadas no curso. É importante verificar o que faz com que essa geração de alunos demonstre pouca motivação e prática de leitura. Porque tanto desinteresse do aluno em ler, em buscar base teórica, que são ações importantes de quem pesquisa? Um dos motivos pode ser a falta de apoio institucional como foi dito. Mas essas atividades precisam ser mais exercitadas no curso. São desafios que precisam ser pensados coletivamente visando ser superados e para que se possa ter maior qualificação na formação docente de Geografia.

Saber que a pesquisa está sendo trabalhada em diversas modalidades, inclusive nas disciplinas e que a pesquisa estimulou os estudantes a pensarem e refletirem sobre sua prática na Universidade foi um aspecto muito positivo. Pensar sobre a pesquisa que ocorre cotidianamente na formação é trazer uma 
reflexão sobre esta, isso possibilita levantar questões e possibilitar uma melhor visão sobre uma prática tão realizada, mas ainda pouco refletida ou pensada de forma teórica. A pesquisa quando é analisada desde seu aspecto teórico contribui para que se valorize mais o ato de pesquisar, ocasionando uma melhor elaboração da pesquisa e obtendo melhores resultados.

A pesquisa contribui na autonomia dos sujeitos, sendo necessária para um profissional que é mediador do conhecimento, no caso o professor. Ela ainda consegue instigar a criticidade que contribui para o docente exercer sua prática em sala, pois ela traz consigo a reflexão dos atos, o professor que reflete sobre seus atos em sala consegue transformar suas capacidades para a docência e para a ciência.

Sobre debater a questão da pesquisa no ensino Freire nos coloca uma questão importante que é "[..] O de que se precisa é que, em sua formação permanente, o professor se perceba e se assuma, porque professor, como pesquisador (1996, p.14), pois a pesquisa só adentra o ensina se o próprio professor se assumir como pesquisador, isso perpassa por sua base que é a graduação porque partindo dela que o docente enxerga como pode atuar em sala de aula e como pode exercer a licenciatura.

A pesquisa faz parte da prática docente, mas para isso necessita ser percebida, refletida e praticada pelo professor. Pensar as práticas que este realiza na graduação é uma forma de levar essa pesquisa a ser pensada e refletida na licenciatura, a qual ainda pode ser voltada por alguns mais para o ensino do que para a pesquisa, fazendo distinção de duas coisas que estão intrinsecamente ligadas que é o ensino e a pesquisa.

Os cursos são compostos por diversos sujeitos, são eles que fazem o curso e o representam, ter a concepção de suas percepções sobre algo que realizam é saber uma parte do processo que ocorre dentro da formação, é perceber se condiz o que está escrito no documento (PPC) com as práticas e visões dos sujeitos. Discutir a formação docente acaba sendo uma forma de trazer maior qualificação para esta. Quando se volta para pesquisa e ensino se possibilita maiores questões e reflexões, podendo potencializar os processos que os discentes ou docentes realizam no curso e na profissão.

O discente deve ter essa busca como algo permanente que penetra na sua 
medula, dessa forma se transformará em um profissional com coerência e qualidade para lecionar Geografia. A expectativa é que esses discentes distribuam o princípio educativo das pesquisas ao atuarem nas escolas, não sendo mero transmissor que apenas reproduz conhecimentos e tendo assim, um papel imprescindível na formação dos sujeitos. A pesquisa tem relevância para os sujeitos que compõem esse curso. Ela tem um papel importante no processo de formação docente porque diminui ou evita a reprodução de conhecimentos, trazendo para o docente que a compreende e a realiza na sua profissão, emancipação e sua atualização permanente.

\section{REFERÊNCIAS}

ANDRÉ, Marli E. D. A. Ensinar a Pesquisar... Como e Para Que? In: Anais do XIII ENDIPE: Educação formal e não formal, processos formativos e saberes pedagógicos: desafios para a inclusão social. Encontro Nacional de Didática e Prática de Ensino; organizadores: Ainda Maria Monteiro Silva et al. Recife: ENDIPE, p. 221- 233, 2006.

BAGNO, M. Pesquisa na escola: o que é, como se faz. São Paulo: Edições Loyola, 2002. v. 1. 102p.

CUNHA, M. S. Dimensão teórico-prática em cursos de licenciatura em Geografia: reflexões a partir da URCA. In: Paulo Sérgio Cunha Farias; Marlene Macário de Oliveira. (Org.). A formação docente em Geografia: teorias e práticas. Campina Grande-PB: EDUFCG; Editora Fonte Viva, 2014, p. 219-246.

DEMO, P. Educar pela pesquisa. 10.ed. Campinas, SP: Autores Associados, 2015. p.160.

DEMO, P. Pesquisa: princípio científico e educativo.12 ed. São Paulo: Cortez, 2006. p.10.

FREIRE, Paulo. Pedagogia da autonomia: saberes necessários à prática educativa. São Paulo: Paz e Terra, 1996. - (Coleção Leitura)

GIROTTO, E. D.; MORMUL, Najla Mehanna . Formação Docente e Educação Geográfica: entre a escola e a universidade. 1. ed. Curitiba: CRV, 2016. v. 1. 118p.

MOREIRA, M. A. Metodologias de Pesquisa em ensino. São Paulo: Livraria da Física, 2011. 
NÓVOA, A. A formação de professores e profissão docente. In: NÓVOA, Antonio (coord.) Os professores e sua formação. Lisboa: Publicações Dom Quixote, 1992.

RIBEIRO, Emerson. Pesquisa e criatividade na formação do professor de Geografia. Geografia Ensino \& Pesquisa, v. 17, p. 107-116, 2013.

SANTOS, Francisco Kennedy Silva dos. A pesquisa como princípio formativo para a prática docente em Geografia. In: Antônio Carlos Pinheiro; Wellington Alves Aragão. (Org.). Formação de professores, metodologias e ensino de geografia. 1ed.Goiânia: Editora Espaço Acadêmico, 2019, v. 1, p. 13-28.

SILVA, F.E. de S.; PINHEIRO, J. Geografia acadêmica e Geografia escolar: a pesquisa como ponto de coesão. In: OLIVEIRA, Stanley Braz de; COSTA SOBRINHO, Werton Francisco Rios da (Org.). Geografia acadêmica e Geografia escolar: a pesquisa como ponto de coesão. Ensino de geografia: teorias e práticas. Piauí: FAM, 2018. 239 p.: ilus.

SOUSA NETO, M. F. de. Aula de Geografia e algumas crônicas. $2^{\mathrm{a}}$ edição. Campina Grande: Bagagem, 2007. p.109.

UNIVERSIDADE REGIONAL DO CARIRI. Projeto Político Pedagógico do curso de Licenciatura Plena em Geografia da URCA. Crato: URCA, 2015. (mimeo).

Recebido em 22 de julho de 2020

Aceito em 17 de dezembro de 2020 